\title{
(S)SAGE reference
}

\section{The SAGE Encyclopedia of Political Behavior}

\section{Equality of Opportunity}

Contributors: Dirk Van de Gaer

Edited by: Fathali M. Moghaddam

Book Title: The SAGE Encyclopedia of Political Behavior

Chapter Title: "Equality of Opportunity"

Pub. Date: 2017

Access Date: June 6, 2017

Publishing Company: SAGE Publications, Inc.

City: Thousand Oaks,

Print ISBN: 9781483391168

Online ISBN: 9781483391144

DOI: http://dx.doi.org/10.4135/9781483391144.n120

Print pages: $255-257$

(C2017 SAGE Publications, Inc.. All Rights Reserved.

This PDF has been generated from SAGE Knowledge. Please note that the pagination of the online version will vary from the pagination of the print book. 
Equality of opportunity is a theory in which personal responsibility plays a central part in determining whether a social system is just. Individuals are held responsible for some characteristics, called efforts, and not responsible for other characteristics, called circumstances. Marc Fleurbaey and Walter Bossert point out that this results in two principles: On the one hand, differences in outcomes that are due to differences in circumstances are objectionable. On the other hand, effort should be adequately rewarded. The former is called the compensation principle, the latter the reward principle.

The three dominant theories about what people are responsible for are responsibility for choice, responsibility for preferences, and responsibility for control. This entry explains these theories, what they mean in terms of equality of opportunity, and how they propose to measure inequality of opportunity. It discusses recent empirical applications and how they link with theories of responsibility. Finally, further issues associated with theories of equality of opportunity are pointed out.

\section{Theories of Responsibility}

A first theory, responsibility for choice, maintains that individuals are responsible for the choices they make from the options they can choose from. This is often referred to as an exante principle, as it evaluates individuals' options, the situation before they make their choice. A second theory is responsibility for preferences. It says that, in the evaluation of each individual's well-being, the trade-offs between different goods, for instance between health and income, must be based on the individual's own relative valuation of these goods. This is an ex-post principle, as the purpose is to evaluate the actual situation of each individual once he has chosen. A third theory, responsibility for control, holds individuals responsible for what they control, such as the number of cigarettes they smoke or the number of hours they work. This principle is also ex-post.

Circumstances are then defined as characteristics that are not efforts. Gender, ethnic origin, and parental background frequently figure as prominent circumstances. Evidently, for each of the theories, what they take as effort can be partly determined by circumstances. What individuals choose from a given set, their trade-offs between different goods and the number of cigarettes they smoke, are at least partly determined by their circumstances. This need not be a problem for responsibility for choice or preferences-it makes sense to hold individuals responsible for their choices or preferences even if these are determined by their circumstances-but, as stressed by John Roemer, it is problematic for the control view. As individuals have no control over their circumstances, they cannot be responsible for the effect of these circumstances on their efforts, such that normatively relevant efforts have to be independent from circumstances.

John Roemer proposes to hold an individual responsible not for his effort as such but for the relative rank of his effort within the distribution of effort of all those that face exactly the same circumstances as he does. Suppose we have 100 descendants from blue-collar and 50 from white-collar parents and that this is the only circumstance we consider. In that case, the proposal is that the blue-collar descendant that smokes the 50th-highest number of cigarettes of all blue-collar descendants and the white-collar descendant that smokes the 25th-highest number of cigarettes of all the white-collar descendants have the same normatively relevant effort as far as smoking behavior is concerned. 


\section{Equality of Opportunity}

With a responsibility-for-choice theory, the focus of attention becomes the set of options individuals can choose from. Equality of opportunity prevails only if all individuals can choose from the same set. Individuals might make different choices from this set, such that they end up with different outcomes, but, as they are responsible for their choice, the resulting differences in outcomes are to be accepted.

With a responsibility-for-preference theory, the focus of attention becomes the quantities of goods individuals have. Marc Fleurbaey and François Maniquet argue that respect for the different trade-offs individuals make between goods is obtained when, for all individuals, their actual combination of goods is exactly as good as another particular combination of goods. For example, in a world with only two goods, health and income, equality of opportunity based on responsibility for preferences is obtained if all individuals find their actual combination of health and income exactly as good as a reference level of health (e.g., perfect health) and a level of income that is the same for everyone. When individuals make different trade-offs between both goods, equality of opportunity can occur even though they have different actual combinations of health and income.

A responsibility-for-control theory can be applied to almost any outcome. Roemer argues it is applicable to individuals' well-being, measured, for instance, by their income, as well as with a partial or more pragmatic view, where the focus is, for instance, on access to education or health or obtained level of education or health. Here equality of opportunity prevails if all those that exercise the same normatively relevant efforts have the same outcome, irrespective of their circumstances. As a result of differences in efforts, again equality of opportunity and inequality of outcome can occur simultaneously.

\section{Measuring Inequality of Opportunity}

To assess the amount of inequality of opportunity with responsibility for choice requires us to collect, for each individual, data of all the options he can choose from. This exercise is plagued with difficulties. First, one can typically observe only the options actually chosen by someone. Second, comparison of unequal sets is difficult. Suppose Ann can choose between "a blue Ferrari" and "going to Rio de Janeiro," while Bob can choose between "a red Ferrari" and "a blue Ferrari." Both have two options. Yet one could argue that Bob's options are very similar and so do not offer a lot of choice. This argument loses force if both Ann and Bob agree that the only thing that makes life worthwhile is possession of a "red Ferrari."

Responsibility for preferences requires us to collect, for each individual, data on his preferences. Fleurbaey and Maniquet advocated the following way to measure the value of the actual combination of goods an individual has and that respects his preferences. Fix, for all goods except one, a reference value (such as perfect health). Determine his equivalent quantity of the remaining good (income), which is such that the reference value of health and this quantity of the remaining good is exactly as good as his actual combination of goods (health and income). This equivalent quantity is then a measure of the individual's well-being, and inequality of opportunity is measured by the inequality in the distribution of equivalent quantities. Few surveys systematically ask respondents for their preferences between different goods. Moreover, obtaining reliable information on an individual's preferences is difficult. These are the main reasons applications of this method are rare, but Koen Decancq and Erik Schokkaert have recently applied the method successfully. 
Responsibility for control can be applied to any outcome and requires information on this outcome and individuals' efforts, as the goal is to measure inequality between people that have the same efforts. Often surveys lack information on efforts. Remember Roemer's proposal that an individual's normatively relevant effort is determined by his relative rank within the effort distribution of those that face exactly the same circumstances. Suppose, in addition, that the outcome is a strictly increasing function of effort. His normatively relevant effort can then be identified, without observing efforts, by his relative rank within the distribution of outcomes of those that face exactly the same circumstances as he. After having identified individuals' normatively relevant effort this way, one can calculate the outcome inequality between those that have the same normatively relevant effort and aggregate these inequalities.

\section{Empirical Applications}

Since the work by François Bourguignon and his coauthors, there has been an explosion of empirical work that measures inequality of opportunity. The most frequently used empirical method is based on the ex-ante principle of responsibility for choice. The basic assumption is that the options an individual can choose from are determined by his circumstances, and all individuals that have the same circumstances can choose from the same options. Next, either one assigns a well-being value to each option, for instance the income it generates, or one borrows from the pragmatic approach advocated by Roemer in the context of responsibility for control and focuses on the quantity of a particular good in each option. The average wellbeing or the average quantity of the good obtained by those that share the same circumstances is taken as a measure of the value of their opportunity set. The inequality in the distribution constructed by assigning to every individual this value of his opportunity set is then a measure of ex-ante inequality of opportunity. Observe that the average well-being or quantity of the good is computed after individuals have made their choice such that it takes into account the effect of circumstances on choices. As a result, this effect influences the inequality between the averages in the constructed distribution and thus measured inequality. Hence, in this approach, individuals are not held responsible for the extent to which their choices are determined by their circumstances.

To apply this method, one has to select circumstances. Selected circumstances typically include parental background (education or occupation), gender, ethnicity, and region of birth. This choice is usually motivated by saying that these characteristics are beyond the control of the individual, although it would be more consistent with the ex-ante view to say they are not chosen by the individual.

Paolo Brunori, Francisco Ferreira, and Vito Peragine compare estimates of inequality of opportunity for income based on the method outlined here for different countries. Scandinavian countries (Norway, Denmark, and Sweden) have the highest equality of opportunity, followed by continental European countries. Next come the Anglo-Saxon countries (Ireland, the United Kingdom, and the United States), and the highest inequality of opportunity is found in Turkey, India, Latin American countries, and South Africa.

\section{Further Issues}

Apart from the decision about what to hold individuals responsible for, there are several other issues when thinking about equality of opportunity and responsibility. A first issue is at which point in their lives we start to hold people responsible. Is there something like a canonical 
moment, such that individuals are not responsible for anything before that moment and are fully responsible after it, or is responsibility something that gradually develops? The latter is probably more reasonable, but accounting for it is fraught with problems, as individuals develop at different rates, which can be hard to determine.

A second issue is that equality of opportunity can conflict with other values and that respecting the efforts of one generation leads to unequal opportunities for the next. The autonomy of the family, which requires that one should abstain from coercively interfering with the consensual relations within the family, is generally acknowledged. Moreover, from the theories about responsibility, it follows that one should respect parental choices, preferences, or actions taken to help their children. Some parents, however, have more means to do so than others. An opportunity-egalitarian perspective implies we should not accept the inequalities that arise for the next generation from the autonomous functioning of the family or from the help parents give to their children.

A third issue is whether equality of opportunity is all that society should be concerned about. Equality of opportunity and individuals ending up with very bad outcomes can coexist. Some people make bad choices, willingly take risks, and see their lives threatened or end up in poverty. Can one really justify not helping them with the argument that they are responsible for their choices or for putting their lives in danger? Several authors propose versions of equality-of-opportunity theories that soften the sometimes harsh conclusions it can lead to.

Finally, responsibility for control requires that individuals have control over some behaviors and thus assumes the existence of free will, which is something not accepted by some neuroscientists.

See alsoDiscrimination; Distributive Justice; Equity Theory; Liberalism; Meritocracy; New Left; Procedural Justice; Procedural Versus Substantive Fairness

Dirk Van de Gaer

http://dx.doi.org/10.4135/9781483391144.n120

10.4135/9781483391144.n120

\section{Further Readings}

Bossert, W. (1995). Redistribution mechanisms based on individual characteristics. Mathematical Social Sciences, 29, 1-17.

Bourguignon, F., Ferreira, F. H. G., \& Menendez, M. (2007). Inequality of opportunity in Brazil. Review of Income and Wealth, 53, 585-618.

Brunori, P., Ferreira, F. H. G., \& Peragine, V. (2013). Inequality of opportunity, income inequality, and economic mobility: Some international comparisons. In E. Paus (Ed.), Getting development right (pp. 85-115). New York, NY: Palgrave Macmillan.

Decancq, K., \& Schokkaert, E. (2016). Beyond GDP: Using equivalent incomes to measure well-being in Europe. Social Indicators Research, 126(1), 21-55.

Fleurbaey, M. (1994). On fair compensation. Theory and Decision, 36, 277-307.

Fleurbaey, M. (2008). Fairness, responsibility, and welfare. Oxford, England: Oxford University Press.

Fleurbaey, M., \& Maniquet, F. (2008). Fair social orderings. Economic Theory, 34, 24-45.

Roemer, J. E. (1993). A pragmatic theory of responsibility for the egalitarian planner. Philosophy and Public Affairs, 22, 146-166.

Roemer, J. E. (1998). Equality of opportunity. Cambridge, MA: Harvard University Press.

Roemer, J. E. (2012). On several approaches to equality of opportunity. Economics and Philosophy, 28, 165-200. 